OPEN ACCESS

Edited by:

Valentí Rull,

Instituto de Ciencias de la Tierra

Jaume Almera (ICTJA), Spain

Reviewed by:

Kangyou Huang,

Sun Yat-sen University, China

Chengyu Weng,

Tongji University, China

${ }^{*}$ Correspondence:

Christy Briles

christy.briles@ucdenver.edu

Specialty section: This article was submitted to

Paleoecology,

a section of the journal

Frontiers in Ecology and Evolution

Received: 30 November 2018 Accepted: 27 March 2019

Published: 18 April 2019

Citation:

Briles C, Serenchenko O, Stevens L, White AJ and Huong NTM (2019) Late Holocene Anthropogenic and Climatic Impact on a Tropical Island Ecosystem of Northern Vietnam

Front. Ecol. Evol. 7:121. doi: 10.3389/fevo.2019.00121

\section{Late Holocene Anthropogenic and Climatic Impact on a Tropical Island Ecosystem of Northern Vietnam}

\author{
Christy Briles $^{1 *}$, Olga Serenchenko ${ }^{1}$, Lora Stevens ${ }^{2}$, A. J. White ${ }^{3}$ and \\ Nguyen Thi Mai Huong ${ }^{4}$
}

1 Department of Geography and Environmental Science, University of Colorado Denver, Denver, CO, United States, ${ }^{2}$ Department of Geological Sciences, California State University Long Beach, Long Beach, CA, United States, ${ }^{3}$ Department of Anthropology, University of California, Berkeley, Berkeley, CA, United States, ${ }^{4}$ Vietnam Institute of Archaeology, Hanoi, Vietnam

Northern Vietnam has a long history of human occupation, warfare, and agriculture; yet, the environmental consequences of human activity are poorly understood due to limited paleoecological records. Results from a terrestrial wetland sediment core from the tropical island, Quan Lan, in Ha Long Bay provide a local record of ecosystem responses to societal shifts due to warfare/instability and climate change. A multiproxy study, including pollen, macro charcoal, fecal stanols, and geochemistry, suggests that native vegetation was abundant and low-level, subsistence wet-rice agriculture and burning were in practice during a time of increased monsoon intensity between 1150 BCE and 950 CE. Between 950 and 1450 CE, a trading and military port was established on Quan Lan Island which served as a major hub of southeast Asian trade and protected the mainland from Mongol invasions. During this period, population near the wetland declined to undetectable levels, rice agriculture declined, burning ceased, and disturbance species expanded. A simultaneous shift toward a more arid climate, with possible extended years of drought, occurred during the Medieval Climate Anomaly based on regional climate records. Without a reliable source of freshwater, rice production declined and/or was supplemented by trade. When the mainland capital near present day Hanoi moved south to Hue after 1450 CE, the port ceased operation. During this time, climate became wetter, and precipitation and surface water more reliable than before. Population near the wetland increased as did burning and rice agriculture. The research has implications for understanding the maintenance of tropical biodiversity amidst long-term human occupation, political unrest, and climate change.

Keywords: Northern Vietnam, tropical island ecosystem, charcoal, fecal stanols, pollen, late holocene, warfare, climate change

\section{INTRODUCTION}

Paleoenvironmental studies provide baselines for future environmental changes, especially in locations with long histories of human occupation and agriculture. In biodiverse tropical locations, such studies are limited but necessary to document the sensitivity and recovery of tropical ecosystems impacted by human pressures and climate variability. Northern Vietnam is a region of high biodiversity, but which also has a history of human occupation extending back at least to the late Pleistocene and agriculture expansion in the late Holocene (Goscha, 2014; Taylor, 2014). 
At the same time, monsoonal precipitation fluctuated in response to changes in incoming solar radiation (Zhang et al., 2008; Zhao et al., 2015), shifts in the latitudinal position of the intertropical convergence zone (Sachs et al., 2009; Yan et al., 2015; Denniston et al., 2016), and variations in ENSO activity (Griffiths et al., 2016). Information on the role of prehistoric human activities and climate change on northern Vietnam tropical environments is sparse. Paleoecological records that do exist for the region are reported for deltaic and estuarine environments, thus providing only broad-scale, regional, and continental interpretations ( $\mathrm{Li}$ et al., 2006, 2009).

Here we report on a multiproxy (pollen, macrocharcoal, geochemistry, coprostanol) paleoenvironmental record spanning the last 3000 years from a freshwater wetland on Quan Lan Island in eastern Ha Long Bay, northern Vietnam. A recent discovery of human burial and artifacts at the Dong Choi archaeological site, a sand dune near Quang Trung Commune, suggests that the island has been occupied for at least 3500-4000 years (Phu et al., 2017). During the Ly and Tran Dynasties of the 11-13th centuries, the island supported a naval base and trading port. Using paleoclimate data from Vietnamese tree-rings (Buckley et al., 2014, 2017) and lake sediments (Stevens et al., 2018) and speleothems from Indonesia (Griffiths et al., 2016) and southern China (Zhang et al., 2008; Zhao et al., 2015), we examine concurrent human and climate drivers influencing this tropical island ecosystem. While the record is low resolution, the limited number of undisturbed terrestrial wetlands in the region, along with this wetland's potential significance in elucidating Vietnamese cultural heritage, makes this an important and novel record.

Since $1943 \mathrm{CE}$, the increase in rice production, aquaculture, and the impacts of war has resulted in an estimated $\sim 30-35 \%$ loss of primary forest, wetland, and mangrove habitats that harbor high levels of biodiversity (Vietnam contains $10 \%$ of the world's flora and fauna) (FOA, 2009). Forest loss, especially of mangroves (31.6\% loss between 2001 and 2008), has been substantial around the Red River Delta and Ha Long Bay with only $\sim 10 \%$ of the area still forested (FOA, 2009; Bui et al., 2014). Although much of the ecosystem degradation can likely be linked to agricultural development, political instability and frequent warfare likely also contributed to a changing landscape. Similarly, in the past, these anthropogenic forces may have helped shaped the environment and biodiversity of organisms.

Early populations in the Red River Delta of northern Vietnam were relatively small and local rulers maintained the land, likely with limited impact on the environment (Taylor, 2014). Around 3000 years ago, rice cultivation and pond aquaculture expanded along the coast and major waterways as technology improved, populations expanded (Maloney, 1991; Chapuis, 1995; Li et al., 2009), and the coastline stabilized (Lam and Boyd, 2003; Tanabe et al., 2006). Fire has been employed extensively in northern Vietnam for rice cultivation to increase the number of crops each year (typically two) by burning stubble left after each harvest (Lasko et al., 2018).

Warfare in SE Asia has been on-going with both internal strife between the three kingdoms (Tonkin, Champa, and Cochinchina) as well as invasions from China and the Mongols.
In warfare, fire is also used extensively. A mainland deltaic record from northern Vietnam has argued that warfare during the past 1500 years, not agriculture, had a major influence on fire regimes in northern Vietnam (Li et al., 2009). The conclusion of the study, while bold, did not address the geographic extent of the impacts of war. However, Li et al. (2009) mention secondary impacts that may also have affected burning, agriculture and ecosystems (e.g., farmers fighting instead of farming, damage to land and/or damage to the economic structure making farming unviable). However, such impacts have not been explored.

Both warfare and agricultural innovation occurred against a backdrop of changing climate. Fluctuations in moisture availability, attributed to the waxing and waning strength of the Asian monsoon, have influenced environments and political, social, and economic development over much of Southeast Asia (Lieberman and Buckley, 2012). Few paleoclimate records exist for SE Asia and even fewer for northern Vietnam. At decadal to interannual resolution, lake sediments from northern Vietnam (Stevens et al., 2018) and tree-rings from Central Vietnam (Buckley et al., 2017) document the modulation of precipitation by ENSO (Pacific Walker Circulation). Intense decades-long droughts triggered famines and contributed to the downfall of empires (Buckley et al., 2010, 2014; Lieberman and Buckley, 2012), but it is less clear how centennial-length climate change may have affected land use. Lake sediments and speleothems offer complex reconstructions of centennial-scale changes in monsoon precipitation in eastern Asia with some records suggesting a wet Little Ice Age (Tan et al., 2011; Yan et al., 2011; Griffiths et al., 2016; Stevens et al., 2018) and others suggesting a wet Medieval Climate Anomaly (Zhang et al., 2008; Yamoah et al., 2016).

This study was undertaken to understand the historic role of Quan Lan Island and the extent of anthropogenic activity. Specifically, the study set out to determine how the backdrop of historical events and climate variability (specifically that during the MCA and LIA climate events) impacted the tropical island ecosystem. These are compared with the human impacts and development activities such as land clearing, burning, and agricultural rice cultivation inferred from pollen and charcoal data. Geochemistry data (organic matter and C:N ratios) provide a measure of productivity and changes in water levels in the wetland, related to changes in climate and land use. Because one record cannot separate climate and human impacts, we examine them in concert, with the reconstruction of climate relying on regional records and societal and political events from historical documents. Finally, gross variations in the local population are inferred from coprostanol data.

\section{SITE DESCRIPTION}

Quan Lan is an elongate island, $18 \mathrm{~km}$ in length, in the Van Don District at the eastern edge of Ha Long Bay (Figure 1). It is mostly sandstone making the terrain gentler, more habitable and accessible compared with the surrounding steep karst islands. The island itself is rich in biodiversity and home to a variety of vulnerable animals, such as the pale capped pigeon and the green turtle, as well as a variety of mangrove 


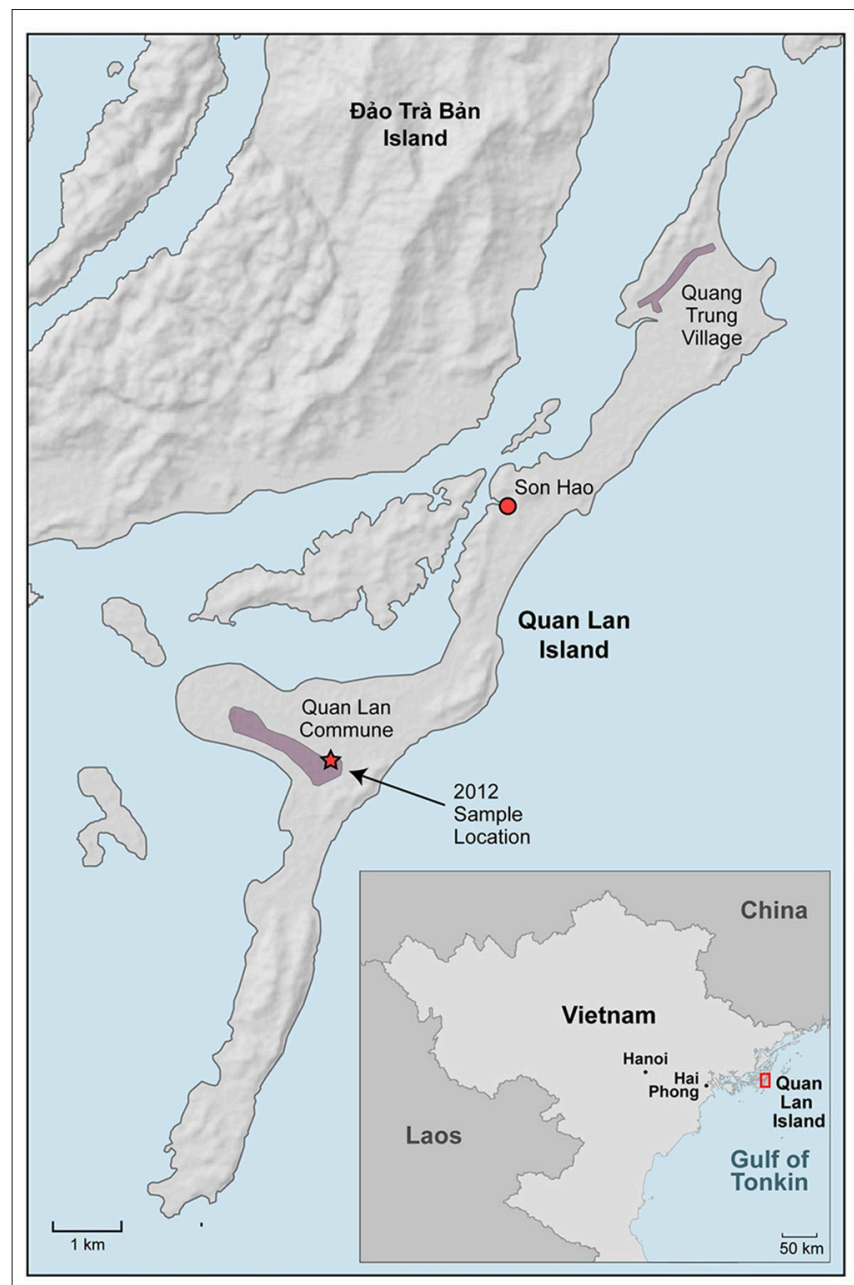

FIGURE 1 | Map of Northern Vietnam and Quan Lan Island. Map showing the location of the Quan Lan Commune and wetland $\left(20.876^{\circ} \mathrm{N}, 107.494^{\circ} \mathrm{E}\right.$; red star), Van Don District. The ancient port of Son Hao is marked by a red dot. (Inset: Location of Quan Lan Island (red box) within northern Vietnam and $\mathrm{Ha}$ Long Bay.)

species, including Bruguiera gymnorrhiza. The natural wetland $\left(20.873460^{\circ}, 107.494736^{\circ}\right)$ where the sediment core was taken is located in the Quan Lan Commune and has been used for centuries as a freshwater source according to the locals (Figure 1). The wetland occupies a low-lying depression and is fed by the sandstone hills to the east, which serve as a buffer to storms. At the time of coring, there was no inflowing stream that feeds the wetland. It is too far removed from the coast and protected by the hills to be affected by storm surges or sand transport from the beach. Modern rainfall capture and storage has made use of the spring obsolete, and in 2014 CE the wetland was destroyed to make room for a paved road that will help bolster international tourism (Figure 2).

The lowland vegetation can be characterized as tropical wet evergreen (and semi-evergreen) and tropical moist deciduous forest (WWF, 1995). Unmodified coastal areas support extensive mangroves, and some species are threatened due to the altered coastline. A tree flora survey of fourteen plots on Quan Lan Island and neighboring islands indicate that the dominant tree species comprise members of Fagaceae, Fabaceae, Myrtaceae, Elaeocarpaceae, Annonaceae, Moraceae, and Euphorbiaceae (Frontier-Vietnam, 2004; Qin et al., 2012). Many of the species are not wind pollinated produce limited pollen, and/or only occur in protected locations on the island. The majority of Quan Lan consists of extensive unfertile sandy soils with low humus that supports scrub and ferns. While sparse, the dominant tree is sheoak (Casuarina) near the wetland; it is planted to stabilize sand dunes but has colonized the island extensively. Agriculture fields (primarily rice) occur to the north of the wetland, but the wetland at the time of coring was not used to grow crops. Locations left fallow are dominated by a variety of fern species.

The climate of $\mathrm{Ha}$ Long Bay is tropical-subtropical. Temperatures vary from 15 to $25^{\circ} \mathrm{C}$. The average annual rainfall is $\sim 2,000 \mathrm{~mm}$ with the summer months receiving half the annual precipitation. In the summer months, southwesterly to southerly winds flow from the Gulf of Tonkin onshore carrying substantial moisture. During the late fall, monsoon winds shift direction, blowing from the northeast along the coast and offshore into the Gulf of Tonkin where they pick up moisture, resulting in more precipitation for Ha Long Bay than the mainland receives.

\section{MATERIALS AND METHODS}

A sediment core, $54 \mathrm{~cm}$ in length, was taken from the $\sim 1$ hectare wetland in December 2012 with a Livingstone piston corer and enclosed in PVC pipe for transport to Monash University in Melbourne, Australia. The core was subsampled at $1 \mathrm{~cm}$ intervals in the Monash University Geography and Environmental Science School's Paleoecology Laboratory. Bagged samples were then shipped to the University of Colorado Denver and California State University Long Beach for further analysis.

\section{Chronology}

Five samples, four bulk sediment and one gastropod, were AMS-dated at Lawrence Livermore National Laboratory. Pollen and charcoal were not abundant enough to isolate at most depths for radiocarbon dates and only one gastropod was found, and radiocarbon dated. A bulk sample at the same depth of the gastropod was measured to estimate the carbon-reservoir error for the wetland. Radiocarbon ages were calibrated, and an age-to-depth model was created using the age-modeling software BACON (Blaauw and Christen, 2011). BACON uses Bayesian statistics, specifically millions of Markov Chain Monte Carlo iterations to reconstruct accumulation histories for sediment deposits. All program defaults were used to produce the age model in BACON. The IntCal13 calibration curve was used for calibrating dates. Raw and calibrated dates are reported in Table $\mathbf{1}$.

\section{Sediment Geochemistry}

Loss-on-ignition (LOI) measures changes in percent organic matter (Dean, 1974). Samples at approximately 1-cm intervals were heated at $100^{\circ} \mathrm{C}$ for $24 \mathrm{~h}$ for dehydration, then $550^{\circ} \mathrm{C}$ 

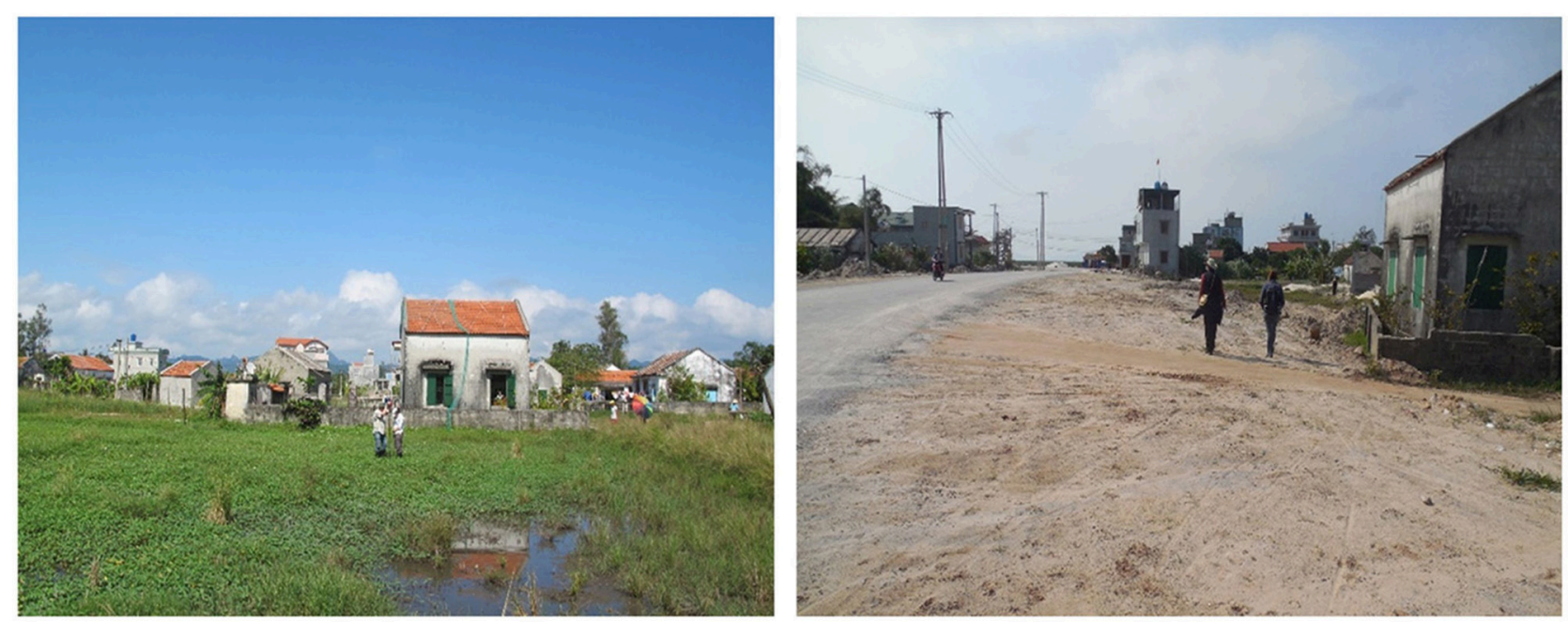

FIGURE 2 | Quan Lan coring site. (Left) December 2012. Looking north (note two windowed house in the background). (Right) December 2015, looking west with the same house to the right of the photograph. The coring site is under the pavement.

TABLE 1 | Radiocarbon dates.

\begin{tabular}{llccccc}
\hline $\begin{array}{l}\text { Lab ID } \\
\text { (CAMS\#) }\end{array}$ & Dated material & Depth $\mathbf{( c m )}$ & $\begin{array}{c}\text { Radiocarbon } \\
\text { date (BP) }\end{array}$ & Error (yr) & $\begin{array}{c}\text { Mean age and upper and lower } \\
\mathbf{9 5 \%} \mathbf{~ C l ~ ( C E / B C E ) *}\end{array}$ & $\begin{array}{c}\text { Mean age and upper and } \\
\text { lower 95\% Cl (cal yr BP) }\end{array}$ \\
\hline 167328 & Gastropod & 10 & 400 & 30 & $1,551(1,677-1,430)$ & $399(273-520)$ \\
167556 & Bulk sediment & 10 & 270 & 30 & $1,551(1,677-1,430)$ & $399(273-520)$ \\
174067 & Bulk sediment & 21 & 905 & 35 & $1,137(1,266-999)$ & $813(684-951)$ \\
167078 & Bulk sediment & 33 & 1,015 & 35 & $916(1,037-699)$ & $1,034(913-1,251)$ \\
174068 & Bulk sediment & 50 & 3,040 & 90 & 643BCE (231CE-1,458 BCE) & $2,593(1,719-3,408)$ \\
\hline
\end{tabular}

*Ages and ranges are from Bacon (Blaauw and Christen, 2011).

for $2 \mathrm{hrs}$ to burn off organics, and finally $900^{\circ} \mathrm{C}$ for another $2 \mathrm{hrs}$ to remove carbonates. The difference in mass after each burn was used to calculate relative percent organic matter and lithogenic material. Data are reported as percent organic carbon. Carbon-to-nitrogen ratios (C:N) also establish a history of ecosystem productivity and the type of waterbody that existed during the span of the record. Ratios $<10$ signify algal organic matter; $>20$ signify terrestrial organic matter; and 10-20 represent a mixture (Meyers and Lallier-Verges, 1999). Carbon-to-nitrogen ratios were measured with a Costech $\mathrm{CHN}$ analyzer. C:N values were calibrated with acetanilide and a controlled reference material (CRM 1944 NIST) was used for quality assurance.

\section{Fecal Stanols}

Coprostanol is a fecal stanol commonly derived from cholesterol in the guts of humans and pigs (Leeming et al., 1996; Bull et al., 2002). Variations in coprostanol concentration have been related to population density and presence/absence of people in a watershed (D'Anjou et al., 2012; White et al., 2018). Fecal stanol concentrations were measured at $3-4 \mathrm{~cm}$ intervals, and at finer intervals in areas of interest, with an Agilent gas chromatograph $(6890 \mathrm{~N}$ series) equipped with a mass selective detector (Agilent 5,973 inert series) following the techniques outlined in White et al. (2018). Stanols were extracted overnight by soxhlet extraction with $200 \mathrm{~mL}$ of dichloromethane and concentrated to a final volume of $0.5 \mathrm{~mL}$ using rotary evaporation under a gentle nitrogen stream. Stanols were derivatized into their trimethlysilyl ethers through a reaction with $\mathrm{N}, \mathrm{O}$-Bistrifluoroacetamide (BSTFA) for $30 \mathrm{~min}$ at $70^{\circ} \mathrm{C}$. A ratio of $5 \beta$-coprostanol to $5 \beta$-coprostanol plus $5 \alpha$ cholestanol, the degradation product of cholesterol formed by soil microbial communities, was calculated to account for fecal degradation through time (Bull et al., 2002; White et al., 2018). By relating $5 \beta$-coprostanol to $5 \alpha$-cholestanol, a comparison is made of stanol input and preservation within soils $(5 \alpha$ cholestanol) to stanol input from feces ( $5 \beta$-coprostanol). Thus, high values of this ratio indicate a large human presence around the wetland and low values indicate a small human presence (White et al., 2018).

\section{Pollen}

Pollen percentages were used to reconstruct changes in local vegetation and rice agriculture around the wetland. Samples were processed using the University of Minnesota LacCore pollen procedures. The pollen extraction methods included the use 
of potassium hydroxide and acetolysis (acetic anhydride and sulfuric acid solution) to remove organics and hydrofluoric acid to remove silicates. Subsamples of the processed samples were analyzed under a compound microscope at $400 \mathrm{x}$ and $\sim 300$ pollen grains were counted per subsample. Pollen databases and taxonomic keys at the Vietnam Institute of Archaeology were used to confirm pollen identification. Poaceae pollen $>40 \mu \mathrm{m}$ was interpreted to be agricultural and based on historical uses in the region likely came from rice (Tweddle et al., 2005; Li et al., 2006). The dominant pollen-types in the record are from agricultural grasses, ferns, Casuariancaceae, with the latter two being disturbance colonizers (Hata et al., 2010; Potgieter et al., 2014). Ferns included those of Dicranopteris, Selaginella, Filicales and Cyclosorus. Sphagnum was included as a Pteridophyte requiring wet, but not fully submerged, conditions. The dominant native pollen types included those of Melastomataceae, Fagaceae, and Acanthaceae. While the pollen types do not represent the main components of the native vegetation, their changing abundances likely reflect general changes in the native flora community. Pollen percentages were calculated based on total terrestrial pollen and spores. Pollen ratios (rice:fern and non-arboreal and arboreal) were calculated using the following equation: $(a-b) /(a+b)$.

\section{Charcoal}

Charcoal accumulation rates were used to provide a local history of landscape burning, specifically the amount of biomass burned. Methods followed Whitlock and Larsen (2001). Macroscopic charcoal $(>125 \mu \mathrm{m})$ was examined every centimeter on $1 \mathrm{~cm}^{3}$ samples. Samples were processed for $24 \mathrm{~h}$ using a mixture of $10 \%$ sodium hexametaphosphate, to break up sediment particles, and $\sim 6 \%$ household bleach (sodium hypochlorite), to oxidize organics. The samples were then sieved at $125 \mu \mathrm{m}$, transferred to petri dishes with water, and charcoal pieces were counted using a stereo-microscope. Charcoal concentrations were divided by deposition time (years $/ \mathrm{cm}^{3}$ ) to calculate charcoal accumulation rates (CHAR).

\section{RESULTS}

\section{Chronology}

Five radiocarbon dates and the age of the top of the core (2013 CE) were used to create a chronology and approximate sedimentation rates (Table 1 and Figure 3 ). The age model is based on four bulk dates and a gastropod. The lack of carbonate on the island would make contamination from old carbon (e.g., hardwater effect) minimal. The radiocarbon age of the gastropod $(400 \pm 30)$ and the sediment $(270 \pm 30)$ are separated by $\sim 70-$ 190 years (accounting for the laboratory error). However, the modeled ages do result in uncertainty including $\sim \pm 100$ years of the mean age reported herein prior to $950 \mathrm{CE}$ and $\pm 500-$ 800 years thereafter. Due to the lack of dates prior to $\sim 950$ $\mathrm{CE}$, and the large age ranges and uncertainties, more confidence is placed on the last millennia, but data are presented for a comparative baseline. Ages hereafter are reported as common era (CE) and before common era (BCE), although figures and tables include calendar years before present (cal yr BP) for reference

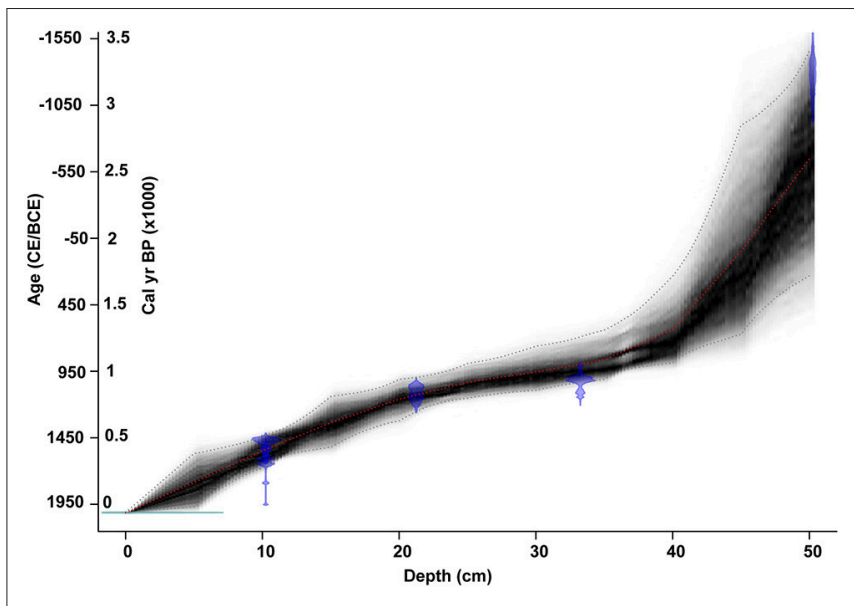

FIGURE 3 | Age-to-depth model for the Quan Lan wetland. The graph shows the Bacon-calibrated ${ }^{14} \mathrm{C}$ dates (transparent blue) and the age-depth model (darker grays indicate more likely calendar ages; gray stippled lines show 95\% confidence intervals; red curve shows single "best" model based on the mean age for each depth.

purposes. The age-depth model suggests a reduction in sediment accumulation (from $\sim 25$ to $\sim 100 \mathrm{yr} / \mathrm{cm}$ ) above $33 \mathrm{~cm}$ depth ( 950 CE).

\section{Lithology and Geochemistry}

The core is composed of sand with visible variations in organic content (Figure 4). We divide the core into three units based on color and composition. The basal unit $(45-54 \mathrm{~cm}$ depth) is composed of a light-gray coarse sand; the middle unit $(15-45 \mathrm{~cm}$ depth), a gray sand; and the top unit $(0-15 \mathrm{~cm}$ depth), a dark, organic-rich sand which fines upward. From about 1150 BCE to $1350 \mathrm{CE}$ (basal and middle lithologic units), organic matter ranges from 1 to $4 \%$. Two short-lived increases in organic content ( 4\%) occur at 500-350 BCE and 950-1050 CE. From $1350 \mathrm{CE}$ to present, organic content increases to $\sim 6 \%$. C:N ratios are high (between 25 and 50) from $1150 \mathrm{BCE}$ to $\sim 1050 \mathrm{CE}$ and then decrease thereafter reaching a ratio of $\sim 12$ by $1350 \mathrm{CE}$.

\section{Fecal Stanols}

The ratio of $5 \beta$-coprostanol to $5 \alpha$-cholestanol is low, $\sim 0.025$, and relatively constant from 1150 BCE to $~ 950$ CE (Figure 5). However, the ratio drops to zero (i.e., undetectable levels of $5 \beta$ coprostanol) from 950 to $1350 \mathrm{CE}$. The ratio then increases to the highest levels $(>0.1)$ toward present.

\section{Pollen}

Prior to $950 \mathrm{CE}$, pollen accumulation rates are very low $(<1,000$ grains $\mathrm{cm}^{-2} \mathrm{yr}^{-1}$ ) and degraded pollen is low $(\sim 4 \%)$, with a maximum of $14 \%$ at the bottom of the core. Agricultural pollen of Poaceae $(>40 \mu \mathrm{m})$ is initially low $\sim 25 \%$, increases to $\sim 48 \%$ by $0 \mathrm{CE}$, and decreases to $\sim 30 \%$ by $950 \mathrm{CE}$ (Figure 5 ). Disturbance species including ferns and those of Casuarinaceae are moderately high. Ferns fluctuate between 10 and 25\% prior to $950 \mathrm{CE}$ and Sphagnum is low $(<10 \%)$. Casuarinaceae steadily decline from 8 to $5 \%$ until $300 \mathrm{CE}$ and increase to $10 \%$ by 950 


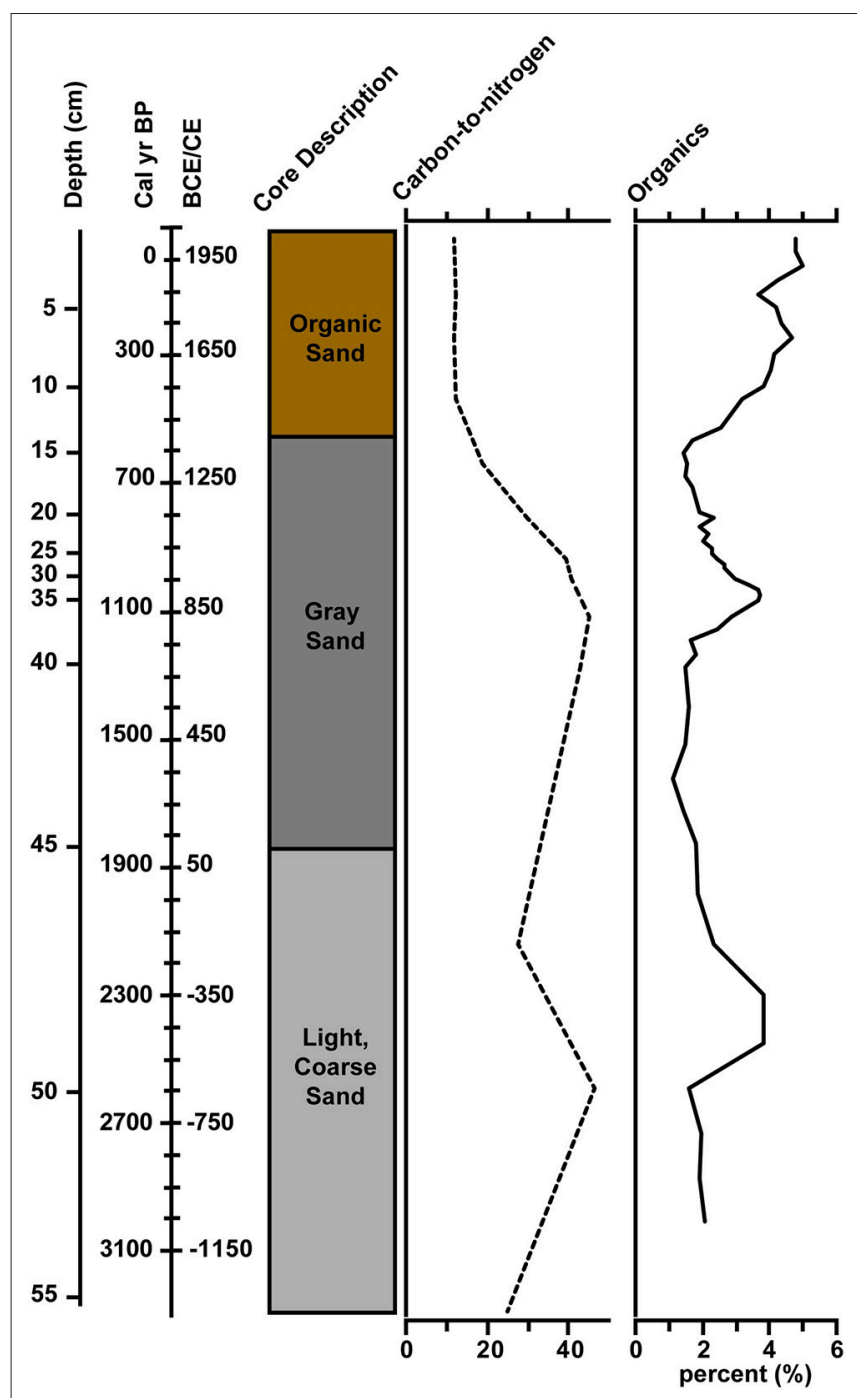

FIGURE 4 | Lithology and geochemistry (C:N ratios and percent organic matter).

CE. Melastomataceae, likely Melastoma candidum, a common invasive shrub found in agricultural areas (Ngo and Webb, 2017), increases from low abundances (1-2\%), peaks at 0 CE (10\%), and decreases back to low levels $(1-2 \%)$ by 950 CE. Native Fagaceae species are initially high (10-20\%) prior to 550 BCE and then decline slowly to $\sim 10 \%$ by $950 \mathrm{CE}$. In addition, native Acanthaceae species occur consistently through the record at $4-5 \%$ until present. The non-arboreal to arboreal pollen ratio is initially low and increases through present.

Between 950 and $1150 \mathrm{CE}$, pollen accumulation rates increase significantly (between 6,000 and 30,000 grains $\mathrm{cm}^{-2} \mathrm{yr}^{-1}$ ) and degraded pollen is minimal (average of $4 \%$; range between 1.5 and 9.5\%). After $1150 \mathrm{CE}$ to present, pollen accumulation rates range between 800 and 3,000 grains $\mathrm{cm}^{-2} \mathrm{yr}^{-1}$ and pollen degradation remains minimal. Percentages of Poaceae $(>40 \mu \mathrm{m})$ decrease after $950 \mathrm{CE}$ to a low of $16 \%$ by $1250 \mathrm{CE}$, and then increase to $28 \%$ by $1450 \mathrm{CE}$. After $1450 \mathrm{CE}$, Poaceae increases to $45 \%$ by $1550 \mathrm{CE}$, decreases to $27 \%$ by $1750 \mathrm{CE}$, and then increases to a high of $47 \%$ toward present. In contrast, fern spores increase significantly to $40 \%$ between 950 and $1250 \mathrm{CE}$ and then decline to $20 \% \sim 1350$ $\mathrm{CE}$ and remain at those levels until present. Sphagnum gradually increases from 10 to $20 \%$, peaking slightly later than the ferns ( $\sim 1350$ vs. $1250 \mathrm{CE}$, respectively), and declining to low levels ( $\sim 5 \%)$ after $\sim 1350 \mathrm{CE}$. The rice to fern ratio is the lowest of the record. Casuarinaceae percentages increase (to 15\%) between 950 and $1250 \mathrm{CE}$, decline to low percentages (5\%) by $1350 \mathrm{CE}$, and remain at those levels through the rest of the record. Fagaceae decreases to $\sim 3 \%$ after $1150 \mathrm{CE}$, and remain at those percentages for the remainder of the record.

\section{Charcoal}

CHAR are low $\left(<0.5\right.$ charcoal particles $\left.\mathrm{cm}^{-2} \mathrm{yr}^{-1}\right)$ prior to 950 CE with the exception of a slight increase to 2 particles $\mathrm{cm}^{-2}$ $\mathrm{yr}^{-1}$ between 750 and $950 \mathrm{CE}$. (Figure 5). CHAR declines to undetectable levels between 950 and $1350 \mathrm{CE}$ and then increases to $\sim 2$ particles $\mathrm{cm}^{-2} \mathrm{yr}^{-1}$ until $1950 \mathrm{CE}$. There is one large charcoal peak at $\sim 1800 \mathrm{CE} \sim 6.5$ particles $\mathrm{cm}^{-2} \mathrm{yr}^{-1}$. After 1950 CE, CHAR drops to $\sim 0.5$ particles $\mathrm{cm}^{-2} \mathrm{yr}^{-1}$ toward present. Generally, macro-charcoal accumulation rates ranging between 0.5 and 10 particles $\mathrm{cm}^{-2} \mathrm{yr}^{-1}$ are common as particles counted are large $(>125 \mu \mathrm{m})$ and do not travel far (Whitlock and Larsen, 2001).

\section{DISCUSSION}

Agriculture and population changes at Quan Lan are contemporaneous with both regional climatic and sociopolitical changes in Vietnam. The proxy data we collected cannot discern between natural and anthropogenic impacts. We do not reconstruct climate based on our record, rather present regionally known climate changes based on independent climate information. The chronology is based on the latest Bayesian techniques, which allow each date to influence the chronology, and therefore fewer dates are needed to produce a reliable chronology. We do not believe the sediment to be contaminated with older/younger carbon given the surrounding sandstone lithology and that two dates at the same depth produced similar ages if considering the slow sedimentation rate and the possible reworking of the gastropod. Individual war events would not be detectable in our record due to the slow sedimentation rate of the wetland. However, anthropogenic modification or climatic change (e.g., Medieval Climate Anomaly or Little Ice Age) spanning hundreds of years would be measurable if they were extensive. Below we compare known changes in climate with the agricultural, population and environmental changes recorded in the Quan Lan sediment record.

\section{Early Occupation and Chinese Influence ( 1150 BCE-950 CE)}

A small human population was likely living near the coring site on Quan Lan Island, $~ 3000$ years ago based on the low fecal stanol values. Even if the $5 \beta$-coprostanol is partly due to animal husbandry (e.g., pigs), this is still evidence of people on 


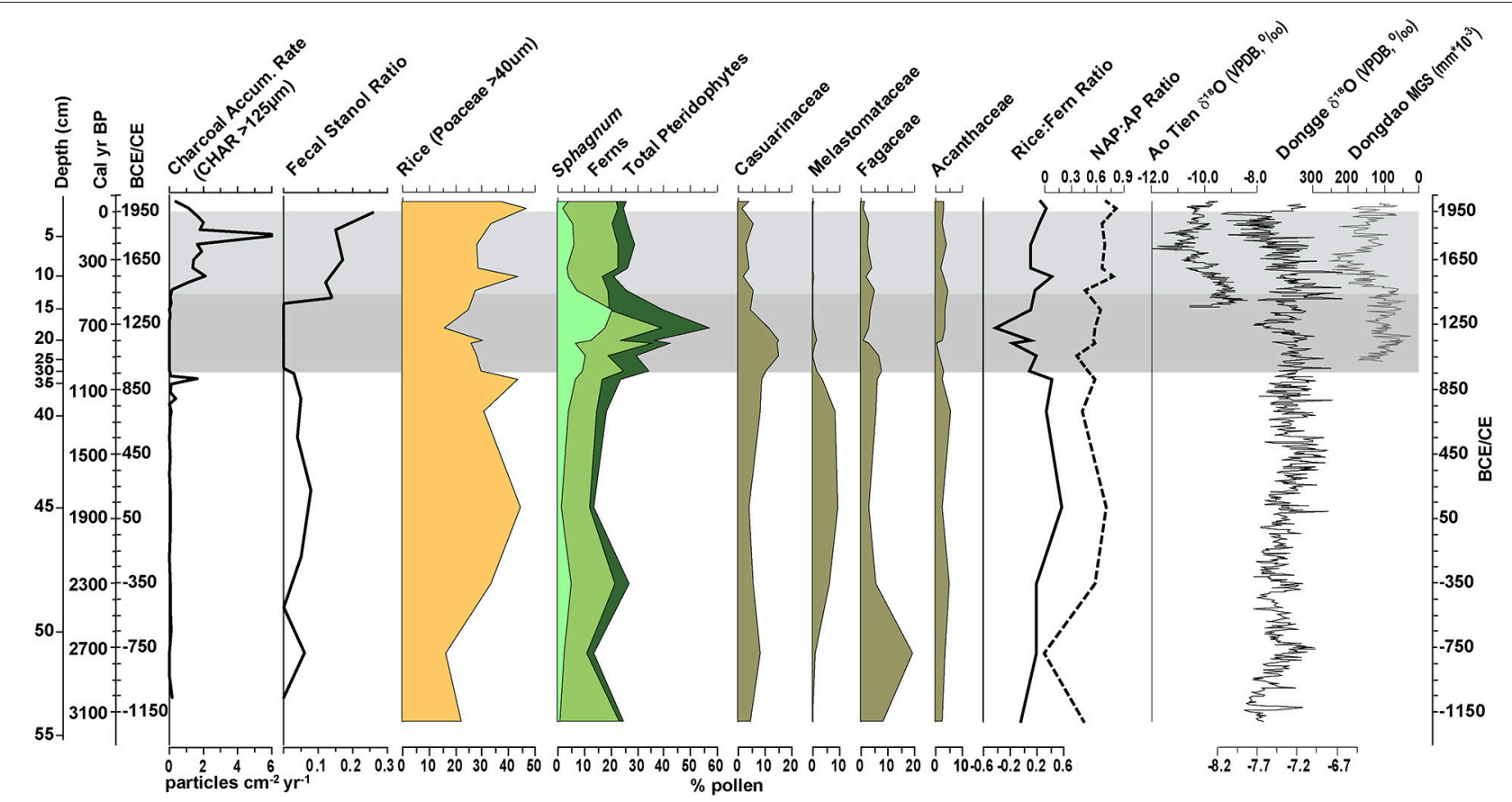

FIGURE 5 | Paleoenvironmental reconstruction. Charcoal accumulation, fecal stanol ratio, and dominant pollen percentages (agricultural:orange; disturbance:green; native:brown). A rice:fern ratio suggests a decline in agriculture during the MCA, and a non-arboreal (NAP):arboreal (AP) ratio indicates fluctuations in native tree species (lower ratio = more native trees) through the record. Regional climate proxies from Ao Tien lake sediments $\left(\delta^{18} \mathrm{O}\right.$; Stevens et al., 2018$)$, northern Vietnam highlands, Dongge Cave speleothem record, southeastern China ( $\delta^{18}$ O; Dykoski et al., 2005; Wang et al., 2005; Zhao et al., 2015), and mean grain size of Cattle Pond sediments on Dongdao of the Xisha Islands in the South China Sea (Yan et al., 2011). The light gray band running through the data is the Little Ice Age (LIA) and the dark gray band the Medieval Climate Anomaly.

the island. An early occupation is consistent with the recent discovery of pottery, stone tools, and obsidian flakes at the Dong Choi archaeology site, northern Quan Lan island, which indicate occupation of the island as early as 3500-4000 years ago (Phu et al., 2017). The wetland may have been seasonally dry as the low percent organic matter suggests rapid oxidation. High carbon-tonitrogen ratios indicate that the organic matter was dominated by terrestrial plants or emergent macrophytes (Meyers et al., 1984). Pollen degradation was moderate in the two bottom most samples and accumulation rates and percent organic matter were low, suggesting possible oxidation early in the record. These factors, along with the dominant lithology of sand, rather than fine grained material, suggest that the area did not maintain standing water throughout the year.

Lack of standing water is not consistent with reconstructions of climate from regional sites and may be the result of wetland hydrology rather than available moisture. For example, paleo-records from Hainan Island suggest wet conditions from 1050 BCE to 1350 CE (Yang et al., 2014). However, Chinese speleothem records suggest a weakened monsoon and generally drier conditions after $\sim 1150 \mathrm{BCE}$ (increasing $\delta^{18} \mathrm{O}$ and $\delta^{13} \mathrm{O}$ ), corresponding to decreasing summer insolation for $30^{\circ} \mathrm{N}$ (Wang et al., 2005). A Laotian speleothem record also suggests a drier local climate during this interval (Yang, 2016). The record from Lake Pa Kho indicates both the wettest (700-1000 CE) and driest (50 BCE-700 CE) periods during this time (Yamoah et al., 2016).
These equivocal climate reconstructions do little to clarify the establishment of the wetland, which was likely only seasonally wet or wet during specific intervals that cannot be resolved with the sedimentation rate.

The presence of rice pollen (Poaceae $>40 \mu \mathrm{m}$ ), while in low percentages in the early part of the record, suggests occupants of Quan Lan Island were likely practicing rice agriculture (Fuller et al., 2011). Wet rice agriculture has been one of the main economic activities of northern Vietnam due to fertile soil and abundant freshwater (Taylor, 2014). The Chinese started incursions into northern Vietnam around 200 BCE, viewing the fertile Red River Delta as valuable land for rice agriculture (Taylor, 2014). While Quan Lan Island is not as fertile as the mainland, the technological and economic influence brought by the Chinese likely made it to the islands indicated by the increase in rice pollen. Early in the record, native species of Fagaceae were in the highest abundances; however, their decline to low levels toward $950 \mathrm{CE}$ suggests clearing of native species for the purpose of growing rice and/or building. The presence of these native species early in the record suggests that the local vegetation was minimally disturbed. Disturbance taxa, such as ferns and species of Casuarinaceae, are most abundant when rice is in lower abundances, while Melastomataceae species, often an invasive in agricultural fields in Vietnam (Ngo and Webb, 2017), are most prevalent when rice is highest prior to $950 \mathrm{CE}$. 
CHAR was minimal early in the record, suggesting that local burning activity (natural or agricultural) was limited. Interestingly, there was a slight increase $\sim 750 \mathrm{CE}$. Chinese officials first introduced their agricultural practices and stone tools to the northern Vietnam highlands during the mid-fifth century. Agricultural practices included burning, which allowed multiple crops to be harvested each year and significantly increased the amount of arable land along with the use of stone tools (Goscha, 2014; Phu et al., 2017). During the 8-9th centuries, there was a movement of people away from the hills (northwest Vietnam) to the coast around the Red River Delta and likely to the islands (Lieberman and Buckley, 2012). The migration of peoples and inception of agricultural burning likely made it to Quan Lan Island, as suggested by the slight increase in charcoal and rice pollen between $\sim 750$ and $950 \mathrm{CE}$.

\section{Societal Instability and Climate Variability (950-1450 CE)}

The nearly absent fecal stanol values suggest that population around the wetland was reduced between 950 and $1450 \mathrm{CE}$. A decreasing trend in C:N ratios and a peak in organic content during this time interval signals increasing algal productivity or reduction in emergent macrophytes, such as rice, and possibly better preservation of organic matter. Both proxies suggest that the depression maintained a standing water body.

During this interval, there is a notable shift in the tropical forest on Quan Lan. Pollen of disturbance species, including those of ferns and Casuarinaceae, increased after $950 \mathrm{CE}$ and were the most abundant by $1250 \mathrm{CE}$ and $1150 \mathrm{CE}$, respectively, while native species of Fagaceae, occurred in smaller abundances than before between 950 and $1450 \mathrm{CE}$. Interestingly, species of Melastomataceae become very limited, possibly indicating a decrease in agricultural productivity, likely limited by the fastgrowing fern species. Sphagnum spores gradually increase and peak $\sim 1350 \mathrm{CE}$, suggesting decreased water levels in the wetland from before and at present. Agricultural rice declines after 950 $\mathrm{CE}$, reaching the lowest levels of the record around $1250 \mathrm{CE}$ and then increasing thereafter, suggesting a decrease in rice production. Burning also ceases as indicated by the absence of charcoal.

The changes in the environment occurred during a period of political instability as the people of northern Vietnam fought for independence from China and established Dai Viet. The Ngo Quyen and then the Dinh Dynasty had control of Dai Viet by $950 \mathrm{CE}$, and the political shift resulted in social, economic, and agricultural expansion along the Red River Delta, initiating trade between the mountain region of northern Vietnam and the Gulf of Tonkin. During the twelfth century, the Ly Dynasty expanded maritime trade, establishing strategic points along the coast for local economic, religious, and defensive purposes (Goscha, 2014). The Van Don port on Quan Lan Island was first mentioned in 1149 CE in the Dai Viet Annals and was one of these strategic points (Kimura and Pollack, 2015). The establishment of the port and naval base likely influenced agriculture on the island.

Some of the change in the environment may have resulted from climate variability. Climate variability is equivocal during the MCA with some studies suggesting wetter conditions in SE Asia (Lieberman and Buckley, 2012). Others, such as the speleothem record from Dongge Cave $(\sim 450 \mathrm{~km}$ north of Quan Lan), indicate a dry climate during the early part of the MCA followed by increasing moisture (Dykoski et al., 2005; Wang et al., 2005; Zhao et al., 2015). The dry-to-wet conditions during the MCA are consistent with the gradual shift in the wetland to more consistent water level as indicated by the increase in algal organic matter (e.g., lower $\mathrm{C} / \mathrm{N}$ ratios). The more coarseresolution record at Cattle Pond in the Xisha Islands in the South China Sea indicates drier winter conditions (interpreted as fewer storms) during this interval, which may be associated with a displacement of the rising limb of the Pacific Walker Circulation to the east (Yan et al., 2011). It is possible that lack of autumn and winter rains made two rice crops difficult.

The complexity of hydroclimate during this period makes correlation with human activity tentative. However, a common climatic thread during this interval is emerging of intense, often decades-long droughts. Tree rings document severe droughts in the eleventh century and early thirteenth century CE in Cambodia (Buckley et al., 2010). The infamous Angkor I and II droughts were 30- and 20- year duration, respectively (Buckley et al., 2014) and have been documented in India (Sinha et al., 2011), Cambodia (Buckley et al., 2010), China (Zhang et al., 2008), and northern Vietnam (Stevens et al., 2018). During the fourteenth century, the Hanoi chronicles document regular droughts and famine (Buckley et al., 2014). The spatial distribution of these severe droughts suggest that Quan Lan was not immune. Lack of summer monsoon precipitation likely dropped the water table in the wetland, allowing Sphagnum moss to grow, and reducing rice agriculture around the wetland for much of this time period. The resolution of our record would not capture individual droughts but rather the longterm consequences. Toward the end of the fifteenth century, available moisture increases in northern Vietnam (Stevens et al., 2018) and this is reflected by an increase in organic carbon and enhanced algal production in the wetland. A nearly simultaneous reappearance of fecal stanols indicate that people are repopulating the region as climate stabilizes and becomes reliably wet.

\section{Modern Northern Vietnam (1450 CE to Present)}

The last $\sim 550$ years of the record suggests increased anthropogenic influence near the wetland. It is a period of intensified cultivation on Quan Lan Island, reflected in the increase in rice pollen (yet not as high as prior to $950 \mathrm{CE}$ until after $1950 \mathrm{CE}$ ), burning, and increased fecal stanols near the wetland. The change occurred rapidly with population increasing first, followed by increased burning and rice agriculture. Ferns and Casuarinaceae declined, while native species remained in low abundances. The wetland maintained standing water, increasing the preservation of organic matter as oxidation decreased. Algal production also increased, reflected in the low $\mathrm{C}: \mathrm{N}$ ratios, in response to water availability, increased nutrient flux from human and livestock waste or both. A reliable water source would have led to more consistent rice cultivation and burning to increase cultivated area and rice production.

The modern period is marked by an increase in effective moisture (e.g., precipitation minus evaporation) in northern 
Vietnam (Yan et al., 2015; Stevens et al., 2018), southern China (Zhao et al., 2015), and Indonesia (Newton et al., 2006; Griffiths et al., 2016). However, the relationship between precipitation and monsoon strength is complicated. Some studies argue that the increase is due to an equatorward contraction of the ITCZ (Denniston et al., 2015; Yan et al., 2015), while others suggest that an amplification or shift of the Pacific Walker circulation is equally important (Yan et al., 2011; Yang et al., 2014, 2016; Griffiths et al., 2016; Yang, 2016; Stevens et al., 2018). Regardless of the cause, more moisture would be favorable for increased rice agriculture and a larger population base.

By the end of the 15th century, Tana (2014) argues that use of the trading base on Quan Lan Island declined as the banks of the Bach Dang River eroded away in the early half of the century. The loss of a mainland port made it more difficult for ships to navigate and transport goods between the Van Don port and the northern capital. Trade was also affected by changes in technology, geographical displacement of the Dai Viet capital to the location of present-day Hue, and the establishment of competing coastal ports. There is also a decrease in trading ceramics at the San Hao archaeological sites from the fifteenth century onward (Phu et al., 2017). The decline in the prominence of the Van Don port after $\sim 1450$ CE coincides with increased burning, rice cultivation, and a significant rise in population in the area around the Quan Lan wetland, suggesting a return of subsistence agriculture near the wetland.

\section{Implications for a Tropical Island Ecosystem}

Understanding anthropogenic impacts on tropical island ecosystems is especially important because they are sensitive to changes in land-use and climate change. Quan Lan Island is being targeted by major international tourism companies for its white sand beaches. As the tourism industry grows, Quan Lan Island, and the surrounding islands of Ha Long Bay, will experience increased environmental pressures unlike those seen in the past. The paleoecological record from Quan Lan Commune highlights the sensitivity of the island ecosystem to outside influences, but also future climate change will likely influence the amount and distribution of precipitation with changes in the Walker Circulation and the position of the ITCZ. Native species have been significantly reduced on the island and future management might consider reestablishing and/or increasing these species and protecting them from future tourism pressures.

\section{CONCLUSIONS}

A multiproxy approach was used to reconstruct the paleoenvironment of Quan Lan Island in Ha Long Bay of northern Vietnam and to place environmental changes within historical, archaeological, and paleoclimate contexts. The results suggest that central power and dynastic shifts, climate variation, wet rice cultivation, and international trade in northern Vietnam all likely played roles in the late Holocene environmental change of the island. Early use of the site (1150 BCE-950 CE) shows limited burning, moderate wet rice agriculture, and abundant native vegetation. During this time, the low but stable population living on the island was likely practicing rice agriculture for subsistence purposes. The site was perhaps only an ephemeral wetland with abundant terrestrial vegetation and sand. A modest increase in rice cultivation and burning $\sim 750 \mathrm{CE}$ occurred as the Chinese brought technology (i.e., stone tools and burning techniques) that allowed wet rice agriculture to expand in the Red River Delta.

The area around the wetland appears to have been largely abandoned between 950 and 1450 CE. Fecal stanols drop to very low levels, signaling a movement of the population away from the area. This shift is matched by undetectable levels of charcoal, abundance of disturbance species, and a decrease in rice pollen. This marked environmental and population change occurred at a time of great political instability resulting from Dai Viet independence from China and shifting dynasties and warfare. However, expansion of wet rice cultivation in the Red River Delta resulted in an increase in the population and trade with surrounding nations. The Van Don port was established in $1149 \mathrm{CE}$ for trade and defense on Quan Lan. It is also possible that climatic conditions made the area around Quan Lan commune unfavorable for subsistence farming. Although there is evidence for an enhanced monsoon during the early part of this period, later aridity and an overall more erratic climate with frequent extreme droughts consistent with prolonged "El Niño-like" conditions.

Approximately $1450 \mathrm{CE}$, population abruptly expanded and burning and rice cultivation subsequently increased. The transition to algal-dominated organic matter suggests that the wetland either expanded or had standing water year-round. This result is not consistent with a drier Little Ice Age, which has been used to explain the decline in agricultural productivity in other parts of southeast Asia. It rather is consistent with climate reconstructions of amplified Walker Circulation and a prolonged "La Niña" state. The return of cultivation at Quan Lan also coincided with the cessation of operation of Van Don port, which may have focused activity from trade back to rice agriculture.

This study suggests that the islands of Ha Long Bay have supported inhabitants for at least 3000 years and that these people practiced rice cultivation and modified the landscape to varying degrees. Anthropogenic impacts, however, significantly increased in the last 500 years due to increased human population. The practice of agriculture resulted in the most significant environmental changes as it often consisted of clearing large areas of land, burning fields, and introducing non-native vegetation. Given the limited paleoecological and paleoclimate information from the region, a study focusing on the remote islands that have experienced little human influence would help identify the influence of natural vs. anthropogenic drivers of environmental change.

\section{AUTHOR CONTRIBUTIONS}

$\mathrm{CB}$ designed the study, conducted the field work, helped to collect and analyse the data, and wrote and coordinated the effort to publish the manuscript. OS collected and analyzed the LOI, 
charcoal and pollen data and helped to write (aspects of the manuscript are based on her BA honors thesis) and edit the manuscript. LS collected and analyzed the carbon and nitrogen data and helped to write and edit the manuscript. AW collected and analyzed the fecal stanol data, wrote sections relying on the data, and edited the manuscript. NH helped with pollen identifications and interpretation, the archaeological history, and edited the manuscript.

\section{FUNDING}

The project was supported by faculty research grants through the University of Colorado Denver (Office of Research Services and the College of Liberal Arts and Sciences) to CB and the California
State University Long Beach to LS. OS received funding from the Undergraduate Research Opportunity Program at CU Denver.

\section{ACKNOWLEDGMENTS}

Special thanks to Drs. Mark Staniforth and Jun Kimura for introducing and involving the researchers in the project and helping with fieldwork and to Dr. Le Lien Thi for her archaeological and historical input and helping with the fieldwork and logistics. All necessary permits and permission were obtained for the study through the Vietnam Institute of Archaeology in Hanoi, which complied with all relevant regulations. Thanks to Dr. Peter Anthamatten at CU Denver for helping to produce the map in Figure 1.

\section{REFERENCES}

Blaauw, M., and Christen, J. A. (2011). Flexible paleoclimate age-depth models using an autoregressive gamma process. Bayesian Anal. 6, 457-474. doi: 10.1214/11-BA618

Buckley, B. M., Anchukaitis, K. J., Penny, D., Fletcher, R., Cook, E. R., Sano, M., et al. (2010). Climate as a contributing factor in the demise of Angkor, Cambodia. Proc. Natl. Acad. Sci. USA. 107, 6748-6752. doi: 10.1073/pnas.0910827107

Buckley, B. M., Fletcher, R., Wang, S. Y. S., Zottoli, B., and Pottier, C. (2014). Monsoon extremes and society over the past millennium on mainland Southeast Asia. Quat. Sci. Rev. 95, 1-19. doi: 10.1016/j.quascirev.2014.04.022

Buckley, B. M., Stahle, D. K., Luu, H. T., Wang, S. Y. S., Nguyen, T., Thomas, P., et al. (2017). Central Vietnam climate over the past five centuries from cypress tree rings. Clim. Dyn. 48, 3707-3723. doi: 10.1007/s00382-016-3297-y

Bui, T. D., Maier, S. W., and Austin, C. M. (2014). Land cover and land use change related to shrimp farming in coastal areas of Quang Ninh, Vietnam using remotely sensed data. Environ. Earth Sci. 72, 441-455. doi: 10.1007/s12665-013-2964-0

Bull, I. D., Lockheart, M. J., Elhmmali, M. M., Roberts, D. J., and Evershed, R. P. (2002). The origin of faeces by means of biomarker detection. Environ. Int. 27, 647-654. doi: 10.1016/S0160-4120(01)00124-6

Chapuis, O. (1995). A History of Vietnam: From Hong Bang to Tu Duc. Westport; London: Greenwood Press.

D’Anjou, R. M., Bradley, R. S., Balascio, N. L., and Finkelstein, D. B. (2012). Climate impacts on human settlement and agricultural activities in northern Norway revealed through sediment biogeochemistry. Proc. Natl. Acad. Sci. USA. 109, 20332-20337. doi: 10.1073/pnas.1212730109

Dean, W. (1974). Determination of carbonate and organic matter in calcareous sediments and sedimentary rocks by loss on ignition; comparison with other methods. J. Sediment. Res. 44, 242-248.

Denniston, R. F., Ummenhofer, C. C., Wanamaker, A. D., Lachniet, M. S., Villarini, G., Asmerom, Y., et al. (2016). Expansion and contraction of the Indo-Pacific tropical rain belt over the last three millennia. Sci. Rep. 6:34485. doi: $10.1038 /$ srep34485

Denniston, R. F., Villarini, G., Gonzales, A. N., Wyrwoll, K. H., Polyak, V. J., Ummenhofer, C. C., et al. (2015). Extreme rainfall activity in the Australian tropics reflects changes in the $\mathrm{El} \mathrm{NiNo/Southern} \mathrm{Oscillation}$ over the last two millennia. Proc. Natl. Acad. Sci. USA. 112, 4576-4581. doi: $10.1073 /$ pnas. 1422270112

Dykoski, C. A., Edwards, R. L., Cheng, H., Yuan, D. X., Cai, Y. J., Zhang, M. L., et al. (2005). A high-resolution, absolute-dated Holocene and deglacial Asian monsoon record from Dongge Cave, China. Earth Planet. Sci. Lett. 233, 71-86. doi: 10.1016/j.epsl.2005.01.036

FOA. (2009). Asia-Pacific Foresty Sector Outlook Study II. Vietnam Forestry Outlook Study. Food and Agriculture Organization of the United Nations. Regional office of Asia and the Pacific, Bangkok.

Frontier-Vietnam (2004). "Bai Tu long bay national park: biodiversity survey and conservation evaluation," in Frontier Vietnam Environmental Research, eds N. Hardiman, Le Xuan Canh, and E. Fanning (Hanoi: Ministry of Agriculture and Rural Development), 1-113.

Fuller, D. Q., van Etten, J., Manning, K., Castillo, C., Kingwell-Banham, E., Weisskopf, A., et al. (2011). The contribution of rice agriculture and livestock pastoralism to prehistoric methane levels: an archaeological assessment. Holocene 21, 743-759. doi: 10.1177/0959683611398052

Goscha, C. (2014). "Sources of Vietnamese tradition," in Critical Asian Studies, Vol. 46, eds. George E. Dutton, Jayne S. Werner, and John K. Whitmore (New York, NY: Columbia University Press, 2012), 366-367.

Griffiths, M. L., Kimbrough, A. K., Gagan, M. K., Drysdale, R. N., Cole, J. E., Johnson, K. R., et al. (2016). Western Pacific hydroclimate linked to global climate variability over the past two millennia. Nat. Commun. 7:11719. doi: $10.1038 /$ ncomms11719

Hata, K., Kato, H., and Kachi, N. (2010). Litter of an alien tree, Casuarina equisetifolia, inhibits seed germination and initial growth of a native tree on the Ogasawara Islands (subtropical oceanic islands). J. Forest Res. 15, 384-390. doi: 10.1007/s10310-010-0199-4

Kimura, J., and Pollack, J. (2015). "Preliminarily study on Van Don: lost ports and lost fleets in northern Vietnam," in Advancing Southeast Asian Archaeology 2013. ed N. H. Tan (Chonburi: SEAMEO SPAFA Regional Centre for Archaeology and Fine Arts), 385-393.

Lam, D. D., and Boyd, W. E. (2003). Holocene coastal stratigraphy and the sedimentary development of the Hai Phong area of the Bac Bo Plain (Red River Delta), Vietnam. Aust. Geogr. 34, 177-194. doi: 10.1080/000491803 01737

Lasko, K., Vadrevu, K. P., Tran, V. T., and Justice, C. (2018). Mapping double and single crop paddy rice with sentinel-1A at varying spatial scales and polarizations in Hanoi, Vietnam. IEEE J. Sel. Top. Appl. Earth Obs. Remote Sens. 11, 498-512. doi: 10.1109/JSTARS.2017.2784784

Leeming, R., Ball, A., Ashbolt, N., and Nichols, P. (1996). Using faecal sterols from humans and animals to distinguish faecal pollution in receiving waters. Water Res. 30, 2893-2900. doi: 10.1016/S0043-1354(96)00011-5

Li, Z., Saito, Y., Dang, P. X., Matsumoto, E., and Vu Q. L. (2009). Warfare rather than agriculture as a critical influence on fires in the late Holocene, inferred from northern Vietnam. Proc. Natl. Acad. Sci. U.S.A. 106, 11490-11495. doi: 10.1073/pnas.0813258106

Li, Z., Saito, Y., Matsumoto, E., Wang, Y. J., Tanabe, S., and Vu, Q. L. (2006). Climate change and human impact on the Song Hong (Red River) Delta, Vietnam, during the Holocene. Quat. Int. 144, 4-28. doi: 10.1016/j.quaint.2005.05.008

Lieberman, V., and Buckley, B. (2012). The impact of climate on Southeast Asia, circa 950-1820: new findings. Mod. Asian Stud. 46, 1049-1096. doi: 10.1017/S0026749X12000091

Maloney, B. K. (1991). Rice agricultural origins: recent advances. GeoJournal 23, 121-124. doi: 10.1007/BF00241396 
Meyers, P. A., Brassell, S. C., and Huc, A. Y. (1984). Geochemistry of organiccarbon in South-Atlantic sediments from deep-sea drilling project leg 75. Initial Reports of the Deep Sea Drilling Project. doi: 10.2973/dsdp.proc.75.129.1984

Meyers, P. A., and Lallier-Verges, E. (1999). Lacustrine sedimentary organic matter records of Late Quaternary paleoclimates. J. Paleolimnol. 21, 345-372. doi: 10.1023/A:1008073732192

Newton, A., Thunell, R., and Stott, L. (2006). Climate and hydrographic variability in the Indo-Pacific warm pool during the last millennium. Geophys. Res. Lett. 33:L19710. doi: 10.1029/2006GL027234

Ngo, T. D., and Webb, E. L. (2017). "Reconciling science and indigenous knowledge in selecting indicator species for forest monitoring," in Redefining Diversity and Dynamics of Natural Resources Management in Asia: Natural Resource Dynamics and Social Ecological Systems in Central Vietnam: Development, Resource Changes and Conservation Issues, Vol 3, eds. T.N. Thang, N.T. Dung, D. Hulse, S. Sharma, and G.P. Shivakoti (Amsterdam: Elsevier Science Bv), 125-138.

Phu, L. V., Lien, L. T., and Hung, B. V. (2017). “Thêm môt di tích văn hóa Ha Long o xã Minh Châu, huyên Vân Don, tinh Quang Ninh [One more site of Ha Long culture found from Minh Chau commune, Van Don district, Quang Ninh province] ", in Nhung phat hien moi ve khao co hoc nam 2016 (Viet Tri City), 726.

Potgieter, L. J., Richardson, D. M., and Wilson, J. R. U. (2014). Casuarina: biogeography and ecology of an important tree genus in a changing world. Biol. Invasions 16, 609-633. doi: 10.1007/s10530-013-0613-x

Qin, X. S., Zhang, R. J., and Xing, F. W. (2012). A study on the flora and vegetation of Cat Dua Island, northeastern Vietnam. Pak. J. Bot. 44, 1229-1232.

Sachs, J. P., Sachse, D., Smittenberg, R. H., Zhang, Z. H., Battisti, D. S., and Golubic, S. (2009). Southward movement of the Pacific intertropical convergence zone AD 1400-1850. Nat. Geosci. 2, 519-525. doi: 10.1038/ngeo554

Sinha, A., Stott, L., Berkelhammer, M., Cheng, H., Edwards, R. L., Buckley, B., et al. (2011). A global context for megadroughts in monsoon Asia during the past millennium. Q. Sci. Rev. 30, 47-62. doi: 10.1016/j.quascirev.2010.10.005

Stevens, L. R., Buckley, B. M., Kim, S., Hill, P., and Doiron, K. (2018). Increased effective moisture in northern Vietnam during the Little Ice Age. Palaeogeogr. Palaeoclimatol. Palaeoecol. 511, 449-461. doi: 10.1016/j.palaeo.2018. 09.011

Tan, L. C., Cai, Y. J., An, Z. S., Edwards, R. L., Cheng, H., Shen, C. C., et al. (2011). Centennial-to decadal-scale monsoon precipitation variability in the semi-humid region, northern China during the last 1860 years: records from stalagmites in Huangye Cave. Holocene 21, 287-296. doi: $10.1177 / 0959683610378880$

Tana, L. (2014). Towards an environmental history of the eastern Red River Delta, Vietnam, c.900-1400. J. Southeast Asian Stud. 45, 315-337. doi: 10.1017/S0022463414000319

Tanabe, S., Saito, Y., Vu, Q. L., Hanebuth, T. J. J., Ngo, Q. L., and Kitamura, A. (2006). Holocene evolution of the Song Hong (Red River) delta system, northern Vietnam. Sediment. Geol. 187, 29-61. doi: 10.1016/j.sedgeo.2005.12.004

Taylor, K. W. (2014). A History of the Vietnamese. Cambridge: Cambridge University Press.

Tweddle, J. C., Edwards, K. J., and Fieller, N. R. J. (2005). Multivariate statistical and other approaches for the separation of cereal from wild Poaceae pollen using a large Holocene dataset. Veg. Hist. Archaeobot. 14, 15-30. doi: 10.1007/s00334-005-0064-0
Wang, Y., Cheng, H., Edwards, R. L., He, Y., Kong, X., An, Z., et al. (2005). The Holocene Asian monsoon: links to solar changes and North Atlantic climate. Science 308, 854-857. doi: 10.1126/science.1106296

White, A. J., Stevens, L. R., Lorenzi, V., Munoz, S., Lipo, C., et al. (2018). An evaluation of fecal stanols as indicators of population change at Cahokia, Illinois. J. Archaeol. Sci. 93, 129-134. doi: 10.1016/j.jas.2018.03.009

Whitlock, C., and Larsen, C. (2001). "Charcoal as a fire proxy," in Tracking Environmental Change Using Lake Sediments: Terrestrial, Algal, and Siliceous Indicators, eds J.P. Smol, H.J.B. Birks, and W.M. Last (New York, NY: Kluwer Academic), 75-97.

WWF, I. (1995). Centres of Plant Diversity. A Guide and Strategy for Their Conservation. Vol. 2: Asia, Australasia and the Pacific. Cambridge: IUCN Publications.

Yamoah, K. A., Chabangborn, A., Chawchai, S., Schenk, F., Wohlfarth, B., and Smittenberg, R. H. (2016). A 2000-year leaf wax-based hydrogen isotope record from Southeast Asia suggests low frequency ENSO-like teleconnections on a centennial timescale. Quat. Sci. Rev. 148, 44-53. doi: 10.1016/j.quascirev.2016.07.002

Yan, H., Sun, L., Oppo, D. W., Wang, Y., Liu, Z., Xie, Z., et al. (2011). South China Sea hydrological changes and Pacific walker circulation variations over the last millennium. Nat. Commun. 2:293. doi: 10.1038/ncomms 1297

Yan, H., Wei, W., Soon, W., An, Z. S., Zhou, W. J., Liu, Z. H., et al. (2015). Dynamics of the intertropical convergence zone over the western Pacific during the Little Ice Age. Nat. Geosci. 8, 315-320. doi: 10.1038/ngeo2375

Yang, H. (2016). Investigating the Impacts of Climate, Hydrology, and Asian Monsoon Intensity on a 13 kyr Speleothem Record from Laos. Ph.D. dissertation, University of California, Irvine, CA.

Yang, H., Johnson, K. R., Griffiths, M. L., and Yoshimura, K. (2016). Interannual controls on oxygen isotope variability in Asian monsoon precipitation and implications for paleoclimate reconstructions. J. Geophys. Res. Atmos. 121, 8410-8428. doi: 10.1002/2015JD024683

Yang, X. Q., Wei, G. J., Yang, J., Jia, G. D., Huang, C. C., Xie, L. H., et al. (2014). Paleoenvironmental shifts and precipitation variations recorded in tropical maar lake sediments during the Holocene in Southern China. Holocene 24, 1216-1225. doi: 10.1177/0959683614540962

Zhang, P., Cheng, H., Edwards, R. L., Chen, F., Wang, Y., Yang, X., et al. (2008). A test of climate, sun, and culture relationships from an 1810-year Chinese cave record. Science 322, 940-942. doi: 10.1126/science.1163965

Zhao, K., Wang, Y. J., Edwards, R. L., Cheng, H., Liu, D. B., and Kong, X. G. (2015). A high-resolved record of the Asian Summer Monsoon from Dongge Cave, China for the past 1200 years. Quat. Sci. Rev. 122, 250-257. doi: 10.1016/j.quascirev.2015.05.030

Conflict of Interest Statement: The authors declare that the research was conducted in the absence of any commercial or financial relationships that could be construed as a potential conflict of interest.

Copyright (c) 2019 Briles, Serenchenko, Stevens, White and Huong. This is an openaccess article distributed under the terms of the Creative Commons Attribution License (CC BY). The use, distribution or reproduction in other forums is permitted, provided the original author(s) and the copyright owner(s) are credited and that the original publication in this journal is cited, in accordance with accepted academic practice. No use, distribution or reproduction is permitted which does not comply with these terms. 